\title{
Investigating the Relationship between Sleep Quality and Mental Health in Chemical Veterans in Comparison with Their Spouses and a Control Group
}

\author{
Seyed Hamzeh Hosseini ${ }^{*}$, Raziyeh Yaghoobi ${ }^{2}$, Fariba Haghdoost ${ }^{2}$, Arghavan Dooshan ${ }^{2}$, \\ Sara Javedani Yekta ${ }^{2}$ \\ ${ }^{1}$ Psychiatry and Behavioral Sciences Research Center, Mazandaran University of Medical Sciences, Sari, Iran; ${ }^{2}$ School of Medicine, \\ Mazandaran University of Medical Sciences, Sari, Iran. \\ Email: *hosseinish20@gmail.com
}

Received November $15^{\text {th }}, 2013$; revised December $10^{\text {th }}$, 2013; accepted January $3^{\text {rd }}, 2014$

Copyright (C) 2014 Seyed Hamzeh Hosseini et al. This is an open access article distributed under the Creative Commons Attribution License, which permits unrestricted use, distribution, and reproduction in any medium, provided the original work is properly cited. In accordance of the Creative Commons Attribution License all Copyrights (C) 2014 are reserved for SCIRP and the owner of the intellectual property Seyed Hamzeh Hosseini et al. All Copyright (c) 2014 are guarded by law and by SCIRP as a guardian.

\begin{abstract}
Aim: This study was aimed to determine the relationship between sleep quality and mental health of veterans in comparison with that of their spouses and a control group. Methods: Thirty-seven chemical veterans with moderate to severe injury based on the standards of Foundation of Martyrs and Veterans Affairs were selected from Mazandaran province. Then, the spouses of 31 of them were selected and 15 of their close relatives also enrolled in the study as the control group. The three groups were evaluated by GHQ for their mental health and Pittsburg Sleep Quality Index (PSQI) for sleep quality. Collected data were analyzed using SPSS software 16 and descriptive and analytic statistical methods. Results: The mean score of mental health in veterans, their spouses and close relatives were $44.13 \pm 14.4,34.19 \pm 15.2$ and $21.73 \pm 17.32$, respectively. The mean scores of PSQI test in veterans, their spouses, and their close relatives were 10.94 $\pm 5.6,8.7 \pm 5.5$ and $4.27 \pm 1$ that the difference was statistically significant among the three groups $(P \leq \mathbf{0 . 0 0 0 1})$. A positive relationship was seen between mental health and sleep quality in veterans and their spouses respectively $(r=0.4, P=0.02)$ and $(r=0.83, P<0.0001)$. Conclusion: Poor sleep quality in chemical veterans compared to their spouses and close relatives could be due to mental health, rather than chemical effects and chronic lung disease. Therefore, treatment of mental health might be an important step to improve the sleep quality of veterans.
\end{abstract}

\section{KEYWORDS}

Sleep Quality; Mental Health; Chemical Veterans

\section{Introduction}

Mental health is more than absence or lack of disease. The positive aspect of mental health, which is emphasized and defined by World Health Organization (WHO), is: "Health is a state of complete physical, mental, and social well-being, and not merely the absence of disease or infirmity [1].” In other words, mental health is a state of welfare in which the individuals know their capabilities and can cope with the normal life stress. They can also be practical and productive in their occupation and

${ }^{*}$ Corresponding author. cooperate with others as a member of the society [2].

Since we spend one-third of our lives asleep and sleep cycle has a great impact on individual's life quality, people's quality of life and activities in the waking hours is largely influenced by their quality of sleep [3-5]. Sleep also affects the immune response of the body [6,7].

There is a complex relationship between the formation of psychiatric symptoms and the occurrence of various events in the life, especially the negative unpredictable threatening ones. Generally, these unwanted events bring about individuals' nervous breakdown and make them susceptible to show mental symptoms like sleep distur- 
bance which is one of the common complications of veterans [8].

One of the most common mental disorders resulting from war is called "post-traumatic stress disorder" [9]. Generally, there is no history of mental illness in these patients and the acute stress reaction recovers after a short period of time. The clinical features of post-traumatic stress disorder include: the painful re-experience of the event, attempt to avoid recalling the incident, flashbacks, difficulty in falling asleep and sleep continuity [10].

A considerable number of chemical veterans suffer from a range of physical and mental disorders which can potentially influence their sleep [11,12]. Research has shown that mental health of chemical veterans is threatened by the incident and the stress caused by the individuals' physical conditions [13]. Despite the passage of so many years from the imposed war, one of the fundamental problems of veterans, especially chemical ones, is their post-war psychological problems and the damage to their mental health and social performance [1]. As mentioned, one of the psychological problems in these patients is sleep disorder; therefore, in this study we aimed to investigate the relationship between sleep quality and mental health in chemical veterans in comparison with that of their spouses and a control group.

\section{Patients and Methods}

The current study is a case-control research in which all the chemical veterans living in Mazandaran province with injury magnitude of moderate and severe, based on the standards of Foundation of Martyrs and Veterans Affairs, took part in this study. The study was approved by the ethics committees of research vice chancellor of Mazandaran University of Medical Sciences and informed consent was obtained from all participants after full explanation of the procedure. The participants were 37 chemical veterans (Group 1), spouses of 31 of them (Group 2) and 15 of their close relatives as the control group (Group 3). All three groups were examined for their mental health through GHQ and for their sleep quality using Pittsburgh Sleep Quality Index (PSQI). Data were analyzed using SPSS software.

PSQI questionnaire yielded a diagnostic sensitivity of $89.6 \%$ and specificity of $86.5 \%$ in distinguishing good and poor sleepers. This questionnaire assesses the quality of sleep of the patients during the last 4 weeks. PSQI has 7 components as follows: subjective sleep quality, sleep onset latency, sleep duration, sleep efficiency (the ratio of sleep time to the time spent in bed), sleep disturbances (individual's waking up during the night), use of hypnotic medication, daytime dysfunction (the problems experienced by the patients during the day due to insomnia).
Each component score has a range of 0 to 3 points. A score of "0" represents normal state of sleep, "1" mild, " 2 " moderate, and finally, a score of " 3 " indicates severe sleep disorder. Then the scores of all seven components are added together and a global score ranging between 0 21 is obtained. A global score of 6 or more shows poor sleep quality $[14,15]$.

Demographic information of the participants including age, gender, marital status, educational level, occupation and veterans' magnitude of injuries was completed.

The General Health Questionnaire (GHQ-28) enjoys the sensitivity of $84 \%$ and specificity of $82 \%$ including questions of the lowest levels of common symptoms in different mental disorders. As a general classification, it can distinguish mental patients from those who consider themselves healthy. Thus, the major goal of the test is to distinguish between mental illness and state of being healthy. The questionnaire consists of 4 sub-scales of 7 questions including somatic symptoms, insomnia and anxiety, social dysfunction, and severe depression; the score for each question ranges from 0 to 3 . The score limit in each scale is between 0 - 21 and the score of less than 7 is considered as mild disorder, 8 - 14 moderate disorder and finally a score of 15 - 21 is an indicator of severe disorder in each scale. The global score is between 0 - 84 and the total score of more than 23 shows poor general health of the person during the previous month [16]. Demographic information including age, occupation, educational level, injury magnitude, educational level of the spouse, all were collected in a questionnaire through the interview carried on by a psychiatrist. Data were analyzed using SPSS software.

\section{Results}

The mean age of veterans was 45 years old (SD of 8.2). Eleven participants were employees, 16 employing state, 4 were of military personnel and 3 were unemployed. The analysis of their educational level showed that one of them was illiterate, four were at primary school level, 5 at secondary school level, 21 had got diploma, and 6 had associate degree and higher. The magnitude of their injuries was as follow: $65 \%$ of them suffered $25 \%-50 \%$ and $34.5 \%$ had $51 \%-70 \%$ of injuries (Table 1 ).

The percentage of sleep quality disorder in three groups of veterans, their spouses and relatives were $86.1 \%, 63 \%$ and $37.5 \%$, respectively, which showed a statistically significant difference among them $(\mathrm{P}=0.009, \mathrm{df}=2)$ and the percentage of those suffering from mental health disorder in three groups of veterans, their spouses and relatives were $94.6 \%, 80.6 \%$ and $33.3 \%$ respectively, indicating statistically significant difference among the three groups $(\mathrm{P}=0.0001, \mathrm{df}=2)$.

The mean scores of General Health Questionnaire 
Table 1. Demographic information of Veterans, their spouses and close relatives.

\begin{tabular}{|c|c|c|c|}
\hline Variables $\quad$ Groups & Veterans & Veterans' Wives & $\begin{array}{c}\text { Close } \\
\text { Relatives }\end{array}$ \\
\hline Age & $45 \pm 8.2$ & $42 \pm 7.7$ & $22 \pm 12.54$ \\
\hline \multicolumn{4}{|l|}{ Gender } \\
\hline Male & 37 & - & 7 \\
\hline Female & - & 31 & 8 \\
\hline \multicolumn{4}{|l|}{ Marital status } \\
\hline Married & 37 & 31 & 4 \\
\hline Single & - & - & 11 \\
\hline \multicolumn{4}{|l|}{ Education Level } \\
\hline Illiterate & 1 & 4 & - \\
\hline Elementary school & 4 & 6 & 2 \\
\hline Junior high school & 5 & 9 & 5 \\
\hline High school & 21 & 9 & 5 \\
\hline Higher education & 6 & 2 & 3 \\
\hline \multicolumn{4}{|l|}{ Occupation } \\
\hline Employee & 11 & 2 & - \\
\hline employing state & 16 & - & - \\
\hline Military personnel & 4 & - & - \\
\hline Student & - & - & 9 \\
\hline Housewife & - & 28 & 3 \\
\hline Unemployed & 6 & - & 3 \\
\hline
\end{tabular}

(GHQ-28) in veterans, their spouses and close relatives were $44.13 \pm 14.4$, $34.19 \pm 15.2$ and $21.73 \pm 17.32$, respectively which showed a significant difference between the three groups $(\mathrm{P}=0.0001)$ (Table 2).

The mean scores of Pittsburg Sleep Quality Index (PSQI) were $10.94 \pm 5.6,8.7 \pm 5.5$ and $4.27 \pm 1$ in veterans, their spouses and close relatives (Table 3); the difference in three groups was statistically significant ( $P$ $\leq 0.001$ ).

There was a relationship between mental health and sleep quality of the veterans and their spouses, which were $(\mathrm{r}=0.4, \mathrm{P}=0.02)$ and $(\mathrm{r}=0.83, \mathrm{P} \pm 0.0001)$, respectively. However, no significant relationship was observed in the mental health and sleep quality of their close relatives $(r=0.01, P=0.96)$ (Table 4$)$.

\section{Discussion}

Our study reveals that $86.1 \%$ of the chemical veterans suffer from poor sleep quality, while only $13.9 \%$ of them had good sleep quality, which is similar to the findings of Tavallaii et al. [17]. Poor sleep quality was observed in $63 \%$ of the veterans' spouses, which was also in correspondence with the findings of Tavallaii et al. for veterans' companions [18]; however, their study did not specify the relation of the companions with the veterans. Few studies have investigated the chemical veterans' sleep conditions and those who have worked on it have studied the veterans' irregular sleep, sleep disorder, periodic changes in sleep, insomnia and nightmares [19-21]. Hence, we could not find a study with a similar design and these 3 groups.

In the current study $37.5 \%$ of veterans' close relatives had poor sleep quality, however, it has been reported $10 \%-60 \%$ in different studies conducted on poor sleep quality with different age ranges (adolescents, normal population and adults) $[18,22,23]$.

From mental health point of view, $94.6 \%$ of the veterans faced some problems; this was similar to the results of Vafaii et al. regarding depression in chemical veterans [24]. In their study, the intensity of depression was higher in chemical veterans than non-chemical ones and the prevalence was higher in this study compared to Zarghami et al., which might be due to the time of investigation and type of the veterans [25]. In the present study, $80.6 \%$ of the veterans' spouses suffered from mental problems; therefore, the prevalence of psychiatric problems is higher than that of Saki and Ghanbari's [26]. A study conducted by Dezhkam comparing the mental health of the spouses of the veterans and those of the psychiatric patients showed that both suffered from mental health problems [27]. The results of the study carried on by Zarabi et al. showed that Iranian spouses with PTSD (Post-Traumatic Stress Disorder) suffered from mental health more than other women. In addition, they had more physical disorders, anxiety, insomnia and poor social performance [28]. The findings of this study indicated that $33 \%$ of veterans' close relatives had mental health problems; this finding is in line with the study worked on the prevalence of mental disorders in general population of Iran in different areas which showed that it varies from 9 to 36 percent, and $36.6 \%$ of the participants over 15 had emotional problems. This shows that our control group can be considered as the representative of the whole society [29].

On the other hand, the current study showed that there is a relationship between mental health and sleep quality of veterans and their spouses; however, such relationship was not found in their close relatives. It should be mentioned that different studies attribute the cause of poor sleep quality in the chemical veterans to different problems such as lung diseases following the chemical intoxication, which occurs in $50 \%$ of cases $[10,11]$ PTSD symptoms reported in $90 \%$ of chemical veterans [30], anxiety disorder reported in 57\%, depression symptoms reported in $57 \%-92 \%$ of cases [20,31,32], and also to taking drugs such as Theophylline that prevents night bronchial contractions but leads to poor sleep quality [33].

According to the present study, the correlation between mental health and sleep quality in veterans and 
Table 2. Comparison of test scores of GHQ in the three groups.

\begin{tabular}{|c|c|c|c|c|}
\hline Grouns & Veterans & Veterans' spouses & Close relatives & $P$ value \\
\hline Scales & Mean \pm SD & Mean \pm SD & Mean \pm SD & \\
\hline Physical symptoms & $4.83 \pm 13.48$ & $4.88 \pm 9.64$ & $5.56 \pm 5.53$ & $0.000 \mathrm{~F}=14$ \\
\hline Anxiety and insomnia & $4.53 \pm 13.08$ & $5.88 \pm 10.45$ & $6.39 \pm 6.86$ & $0.001 \mathrm{~F}=7$ \\
\hline Performance failure & $4.37 \pm 11.43$ & $4.62 \pm 9.32$ & $4.69 \pm 7.06$ & $0.007 \mathrm{~F}=7$ \\
\hline Depression symptoms & $5.07 \pm 6.83$ & $4.63 \pm 4.80$ & $4.28 \pm 2.60$ & $0.015 \mathrm{~F}=4.4$ \\
\hline GHQ global score & $44.13 \pm 14.4$ & $34.19 \pm 15.2$ & $21.73 \pm 17.32$ & $0.0000 \mathrm{f}=12$ \\
\hline
\end{tabular}

Table 3. Comparison of scores of Pittsburg Sleep Quality Index (PSQI) in the three groups.

\begin{tabular}{|c|c|c|c|}
\hline Groups & Veterans & Veteran's spouses & Close relatives \\
\hline & Mean \pm SD & Mean \pm SD & Mean \pm SD \\
\hline Subjective sleep quality & $0.92 \pm 2.09$ & $1.15 \pm 1.4$ & $0.99 \pm 0.87$ \\
\hline sleep onset latency & $0.99 \pm 2.06$ & $1 / 31 \pm 1 / 84$ & $1.03 \pm 0.66$ \\
\hline sleep duration & $0.92 \pm 2.41$ & $1 / 36 \pm 1 / 88$ & $1.21 \pm 0.66$ \\
\hline Sleep efficiency & $1.38 \pm 1.50$ & $1 / 27 \pm 1$ & $1.21 \pm 0.66$ \\
\hline sleep disturbances & $1.12 \pm 2.34$ & $1 / 60 \pm 2 / 23$ & $1.38 \pm 1.71$ \\
\hline sleeping medication & $1.27 \pm 1.72$ & $1 / 26 \pm 0 / 95$ & $1.18 \pm 0.62$ \\
\hline daytime dysfunction & $0.96 \pm 1.4$ & $0 / 95 \pm 1 / 21$ & $1.18 \pm 0.62$ \\
\hline PSQI global score & $10.94 \pm 5.6$ & $8.7 \pm 5.5$ & $4.27 \pm 1$ \\
\hline
\end{tabular}

Table 4. Comparison of results of GHQ and PSQI in the three groups.

\begin{tabular}{ccccc}
\hline \multirow{2}{*}{ Groups } & \multicolumn{3}{c}{ Questionnaires } & P-value \\
\cline { 2 - 4 } & GHO scores & PSQI scores & 0.4 \\
Veterans & $44.13 \pm 14.4$ & $10.94 \pm 5.6$ & 0.02 \\
Veterans' spouses & $34.19 \pm 15.2$ & $8.7 \pm 5.5$ & 0.83 & 0.0001 \\
Close relatives & $21.73 \pm 17.32$ & $4.27 \pm 1$ & 0.01 \\
\hline
\end{tabular}

their spouses was positive and strong, although their spouses did not have any history of lung diseases. Thus, it seems that the major predictor of sleep quality is mental health, including PTSD, other anxiety disorders and depression. It can be concluded that by appropriate treatment of the psychiatric disorders in veterans, sleep quailty will likely improve.

It is recommended that other researchers design nationwide studies and simultaneously investigate the pulmonary problems and match the veteran groups in order to confirm and generalize the investigated hypothesis of this study.

\section{Competing Interests}

None declared.

\section{REFERENCES}

[1] G. R. Karami, M. Amiri, J. Ameli, H. Kachooei, K.
Ghodoosi, A. R. Saadat, et al., "Psychological Health Status of Mustard Gas Exposed Veterans," Journal of Military Medicine, Vol. 8, No. 1, 2006, pp. 1-7.

[2] WHO, "Investing in Mental Health," World Health Organization, Geneva, 2003.

[3] M. Kupperman, D. Lubeck, P. D. Mazonson, D. L. Patrick, A. L. Stewart, D. P. Buesching and S. K. Fifer, "Sleep Problems and Their Correlates in a Working Population,” Journal of General Internal Medicine, Vol. 10, No. 1, 1995, pp. 25-35.

http://dx.doi.org/10.1007/BF02599573

[4] R. Asplund, "Sleep Disorders in the Elderly," Drugs Aging, Vol. 14, No. 2, 1999, pp. 91-103. http://dx.doi.org/10.2165/00002512-199914020-00002

[5] N. S. Gooneratne, T. E. Weaver, J. R. Cater, F. M. Pack, H. M. Arner, A. S. Greenberg and A. I. Pack, "Functional Outcomes of Excessive Daytime Sleepiness in Older Adults," Journal of the American Geriatrics Society, Vol. 51, No. 5, 2003, pp. 642-649. http://dx.doi.org/10.1034/j.1600-0579.2003.00208.x

[6] P. A. Bryant, J. Trinder and N. Curtis, "Sick and Tired: 
Does Sleep Have a Vital Role in the Immune System," Nature Reviews Immunology, Vol. 4, No. 6, 2004, pp. 457467. http://dx.doi.org/10.1038/nri1369

[7] R. M. Benca and J. Quintas, "Sleep and Host Defenses: A Review,” Sleep, Vol. 20, No. 11, 1997, pp. 1027-1037.

[8] J. A.Talbott, J. C. Ballenger, A. F. Breier, R. J. Frances, H. Y. Meltzer, H. F. Schowalter, Et Al., "Year Book of Psychiatry and applied Mental Health,” Mosby, 1997.

[9] H. I. Kaplan and B. J. Sadok, "Synopsis of Psychiatry," 8th Edition, Kathleen Courtney Millert, Baltimore, 1998.

[10] M. J. Murphy, L. Kwan and L. Silder, "Blue Print Psychiatry,” (Translated by N. Pourfakary), Free Tabriz Publishing, 2001.

[11] A. Emad and G. R. Rezaian, "The Diversity of the Effects of Sulfur Mustard Gas Inhalation on Respiratory System 10 Years after a Single Heavy Exposure: Analysis of 197 Cases,” Chest, Vol. 112, No. 3, 1997, pp. 734-738. http://dx.doi.org/10.1378/chest.112.3.734

[12] M. H. Bijanti, S. K. Hosseini, S. H. Mostafavi, S. A. Alavi, "High Resolution CT in Chronic Pulmonary Changes after Mustard Gas Exposure,” Acta Radiologica, Vol. 44, No. 3, 2003, pp. 241-245. http://dx.doi.org/10.1080/j.1600-0455.2003.00073.x

[13] C. M. Pechura and D. P. Rall, "Relationship of Mustard Agent and Lewisite Exposure to Psychological Dysfunction. Veterans at Risk: The Health Effects of Mustard Gas and Lewisite,” The National Academies Press, Washington DC, 1993.

[14] Dj. Buysse, C. F. ReynoIds III, T. H. Mink, S. R. Berman and D. J. Kupfer, “The Pittsburgh Sleep Quality Index: A New Instrument for Psychiatric Practice and Research,” Psychiatry Research, Vol. 28, No. 2, 1989, pp. 193-213. http://dx.doi.org/10.1016/0165-1781(89)90047-4

[15] A. Ebrahimi Afkham, M. F. Ghalebandi, M. Salehi, A. Kafian Tafti, Y. VaKili and E. AKHIaghi Farsi, "Study of Sleep Parameters and Factors Effecting on Sleep Quality of Outpatients Clients of Selected Rasol-EAKram Hospital Clinics," Journal of Iran University of Medical Sciences, Vol. 58, No. 15, 2008, pp. 31-37.

[16] N. Yaghoubie and M. Nasr, "Epidemiology of Psychiatric Disorders in Urban and Rural Areas of Someesara (Gilan 1995)," Iranian Journal of Psychiatry and Clinical Psychology, Vol. 4, 1995, pp. 55-65.

[17] S. A. Tavallaie, S. H. Assari, M. Najafi, M. Habibi and M. Ghanei, "Study of Sleep Quality in Chemical-WarfareAgents Exposed Veterans," Journal of Military Medicine, Vol. 6, No. 4, 2005, pp. 241-248.

[18] S. A. Tavalaei, S. H. Asaari and M. Habibi, "Subjective Sleep Quality in Chemical Warfare Veterans," Iranian Journal of Psychiatry and Clinical Psychology, Vol. 12, No. 3, 2006, pp. 263-269.

[19] C. A. James and J. R. Romana, "Psychological Coaslties Resalting from Chemical and Biological Weapons," Journal of Military Medicine, Vol. 166, 2001, pp. 21-22.

[20] W. F. Page, "Long-Term Health Effects of Exposure to Sarin and Other Anticholinsterase Chemical Warfare Agents,” Mill Med, Vol. 168, No. 3, 2003, pp. 239-245.
[21] F. Madarshahiean, "Comparison of Coping with Direct and Indirect Consequences of War Stress in Later Life between Chemical and Physical War Injured,” Journal of Military Medicine, Vol. 5, No. 2, 2003, pp. 117-120.

[22] S. Ancoli-Israel and T. Roth, "Characteristics of Insomnia in the United States: Results of the 1991 National Sleep Foundation Survey," Sleep, Vol. 22, Suppl. 2, 1999, pp. 347-353.

[23] D. E. Ford and D. B. Kamerow, "Epidemiologic Study of Sleep Disturbance and Psychiatric Disorders," Journal of the American medical Association, Vol. 262, No. 11, 1989, pp. 1479-1484. http://dx.doi.org/10.1001/jama.1989.03430110069030

[24] B. Vafai and A. Seidy, "Study of the Prevalence and Intensity of Depression in 100 Devotees with Chemical and Non-Chemical War Injuries (30-70\%) of Imposed War in Tabriz,” Journal of Military Medicine, Vol. 5, No. 2, 2003, pp. 105-110.

[25] M. Zarghami, A. R. Khalilian, A. H. Tirgari, H. Khoshsorour and A. N. Rezai, "Epidemiology of Cognitive Psychological Disorders among Veterans in Sari (1997)," Mazandaran University of Medical Sciences Journal, Vol. 98, No. 7-8, 1997, pp. 17, 18.

[26] M. Saki and A. Hanbari, "Mental Health Assessment in Spouses of Spinal Cord Injured War Survivors in Lorestan, Osole,” Behdasht Ravani, Vol. 18, 2005, pp. 7-14.

[27] M. Dejkam and A. Aminoroaya, "The Comparison of Mental Health between Psychologic Veterans Spouses who Reffered to Sadr Hospital and Psychologic Pation Spouse," Janbaz and Family Congress, JMERC, 2004, pp. 113-122.

[28] H. Zarrin, K. Nahafi, M. Shirazi, H. Farahi, F. Nazafi and M. Tadrisi, "The Impact of Posttraumatic Stress Disorder on Partner of Iranian Reterans," Acta Medica Iranica, Vol. 46, 2008, pp. 124-128.

[29] A. A. Noorbala, Bagheri S. A. Yazdi, M. T. Yasamy and K. Mohammadi, "Mental Health Survey of the Adult Population in Iran,” British Journal of Psychiatry, Vol. 184, 2004, pp. 70-73.

http://dx.doi.org/10.1192/bjp.184.1.70

[30] S. J. Tavalaie and R. Javadi Veshki, “Assessment of Mental Health Status of Chemical Weapons Injured Veterans in Sardasht in 2001," MGP Thesis, Baghiatallah Medical University, 2002.

[31] F. Kheirkhah, K. Bizhani, S. A. Hosseini and J. Zeinali, "Prevalence of Depressive Symptoms in Chemical Weapons Injured Veterans of War in Golestan and Mazandaran Province in 2000," Congress of Military Medicine (With Emphasis on Experience, 8 Years War), Iran, 1517 October 2001.

[32] S. Momtasi, "Abstracts of the Sixth Congress of Psychiatry and Psychology Research in Iran," Shahid Beheshti University Publication, 2000.

[33] G. B. Rhind, J. J. Connaughton, J. MCFie, N. J. Douglas and D. C. Flenley, "Sustained Release Choline Theophlinate in Nocturnal Asthma,” British Medical Journal, pp. 1605-1607. 